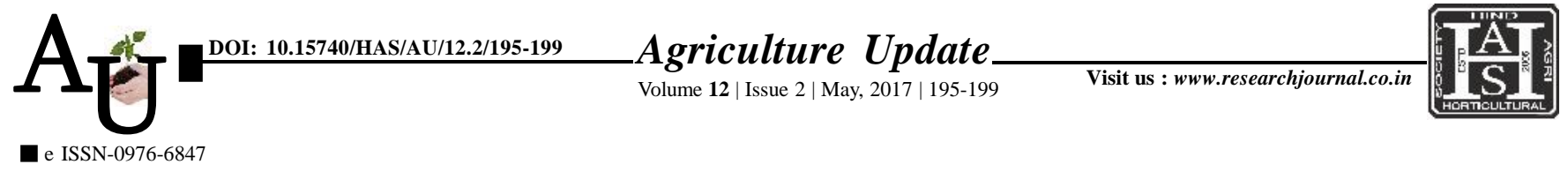

\title{
Research Article: Constraints in adoption of recommended practices by the respondents extended through Agricultural Polyclinic
}

\section{S.G. PURI AND S.D. WANGIKAR}

Article Chronicle: Received : 30.01.2017;

Revised :

26.02.2017;

Accepted :

07.03.2017

KeY Words:

Beneficiaries of agricultural Polyclinics, Constraints

Author for correspondence :

\section{S.G. PURI}

Department of

Extension Education,

Marathwada Krishi

Vidyapeeth, PARBHANI

(M.S.) INDIA

Email:sgpuri2@gmail.com

See end of the article for

authors' affiliations
SUMMARY : The present study was undertaken in Parbhani, Nanded and osmanabad districts of Marathwada region. From these selected districts, two talukas in each district on the basis of earlier establishment of 'agricultural polyclinics' were selected and two 'agricultural polyclinics' from each district were selected on the basis of same principle. From each list of polyclinic beneficiary, 25 respondents were drawn by $\mathrm{n}^{\text {th }}$ method of random sampling. Thus final sample comprised of 150 respondents. A substantial percentage $(58.00 \%)$ of the respondents were of middle aged. As regards education a significant $(37.33 \%)$ per cent of the respondents were possessing higher secondary level of education. 33.33 per cent had farming as main occupation, 59.33per cent were having semi medium size of land holding with an annual income of medium category $(57.33 \%)$ having medium level of social participation $(63.33 \%)$ and medium risk orientation $(69.33 \%)$. Majority of the respondents $(81.34 \%)$ had medium contacts and medium economic motivation $(73.34 \%)$. Two top most constraints expressed by the respondents were lack financial support from 'agricultural polyclinic' and not undergoing any training or demonstration of high tech agriculture based on shed net, green house and low cost green house.

How to cite this article : Puri, S.G. and Wangikar, S.D. (2017). Constraints in adoption of recommended practices by the respondents extended through Agricultural Polyclinic. Agric. Update, 12(2): 195-199; DOI : 10.15740/HAS/AU/12.2/195-199. 